Part of Journal of Research of the National Bureau of Standards, Volume 36, June 1946

\title{
CRYSTALLIZATION OF UNVULCANIZED RUBBER AT DIFFERENT TEMPERATURES ${ }^{1}$
}

\author{
By Lawrence A. Wood and Norman Bekkedahl
}

\section{ABSTRACT}

The crystallization and melting of unvulcanized natural rubber in the unstretched state have been investigated at different temperatures. Change of volume has been used as a quantitative measure of the extent of crystallization, and mercury-filled dilatometers containing the rubber have been used for the volume measurements.

Crystallization was observed to occur at temperatures between $-50^{\circ}$ and $+15^{\circ} \mathrm{C}$ and to be most rapid at about $-25^{\circ} \mathrm{C}$. The final decrease of volume on crystallization was usually found to lie between 2.0 and 2.7 percent.

The melting of the crystalline rubber was found to occur over a range of temperature and to be strongly dependent on the temperature at which the crystals were formed. The temperature at which the beginning of melting occurs is from 4 to 7 degrees above the temperature of crystallization. The range of melting is about 35 degrees at the lowest temperatures and decreases to about 10 degrees at the highest. The same range of temperature of melting is obtained regardless of the extent of the crystallization.

\section{CONTENTS}

Introduction ...... 489

II. Experimental procedure.

III. Experimental results

1. Rate of crystallization

2. Melting of crystallized rubber $\ldots \ldots \ldots 2$

3. Partial crystallization

4. Recrystallization of rubber

5. Stark rubber.

IV. Discussion of results

1. Rate of crystallization

2. Lower limit of temperature of crystallization _...

3. Upper limit of temperature of crystallization

4. Temperature at which crystallization is most rapid_. 501

5. Magnitude of the volume change on crystallization....... 501

6. Melting of crystallized rubber _. 502

7. Recrystallization

8. Nature of the crystals

V. References_._.

\section{INTRODUCTION}

Crystals may be formed in natural rubber under quite varied experimental conditions. Different combinations of stretching and

1 Presented at the meeting of the Division of High Polymer Physics of the American Physical Society held at Columbia University, New York, N. Y. on January 26, 1946. This paper also appears in J. Applied Phys. 17, 362 (1946). 
cooling have been used to induce crystallization in unvulcanized and in vulcanized rubber. The appearance and disappearance of crystals have been studied by observations of the volume $[5,8,32],{ }^{2}$ heat capacity [6], light absorption [53], birefringence [40, 58, 63, 67, 74], $\mathrm{X}$-ray diffraction [22], and hardness [53] and other mechanical properties [42]. There has, however, been no comprehensive study of the effect of temperature on the crystallization. The present investigation was undertaken in order to explore this field.

In the work reported here it has been the aim to study the crystallization at different temperatures under the simplest possible conditions. The main features of the crystallization of vulcanized rubber have been shown [8] to be similar to those of the crystallization of unvulcanized rubber, the vulcanization causing a decrease in the rate of crystallization. Consequently, unvulcanized rubber was selected for study. Stretching obviously adds complication to the experimental conditions, and so was not employed. Of the different methods of measuring crystallization it seems that change of volume is the simplest and best adapted to yielding quantitative data about the course of the crystallization or fusion. The present work, therefore, is concerned with a general study of the volume changes in unvulcanized rubber at different temperatures.

\section{EXPERIMENTAL PROCEDURE}

The volume changes of the specimens were measured by the use of dilatometers with confining liquids. The method incorporates some improvements over that previously used $[5,8]$. The dilatometers were made of Pyrex glass, and each consisted merely of a bulb with a capillary tube sealed to it. Changes in volume could be calculated from measurements of changes in the height of the confining liquid in the capillary tube. Mercury was selected as the confining liquid because it seems to have no effect on rubber, even when the two are in contact for periods of several years. Some absorption, swelling, and softening usually occur with other liquids. The specimens were strips cut from plantation smoked sheet rubber.

The construction of the dilatometers and the procedure of filling them were somewhat improved during the course of the work reported here. In the later dilatometers, the capillary tubes were about $2 \mathrm{~mm}$ in inside diameter and about $500 \mathrm{~mm}$ in length. They were specially selected capillaries, but were not of the precision-bore type recently developed. They were graduated in millimeters along their length. The tubes were calibrated by sealing a stopcock to one end, and observing the lengths of weighed amounts of mercury at five or more different points along each tube. The maximum variation in crosssectional area along a single capillary was found to be about 3 percent in most cases. Each capillary was then sealed to a glass tube about $15 \mathrm{~mm}$ in inside diameter, the other end of the tube being left open. Into the glass tube were inserted a weighed rubber specimen and a hollow glass bulb about 40 or $50 \mathrm{~mm}$ long. Finally, the open end of the glass tube was sealed off to form the bulb of the dilatometer.

3 Figures in brackets indicate the literature references at the end of this paper. 
This construction made it possible to avoid heating of the specimen during the sealing operation without unduly increasing the net volume of the dilatometer bulb. In most cases the volume of the specimen was between two and three times the volume of the mercury in the bulb of the dilatometer. The effect of the insertion of the hollow bulb is equivalent to a mere reduction of the net volume of the dilatometer bulb. As the inner hollow bulb was made of the same type of glass as the rest of the dilatometer, neither its volume nor its expansivity entered directly into any of the calculations.

The dilatometer was next evacuated for several days to remove gas from the specimen. Mercury was then admitted to the evacuated system through a two-way stopcock, until it filled the dilatometer bulb and stood at a suitable height in the capillary. Occasionally it was necessary to carry out further removal of gas until the height of the mercury in the capillary did not change by more than a few millimeters as the pressure was again raised to that of the atmosphere. Calculation showed that the gas remaining under these conditions would have negligible effect on the observed specific volume and expansivity. The dilatometer was weighed before and after the addition of the mercury.

The volumes of specimen and mercury at $25^{\circ} \mathrm{C}$ were determined from their weights and densities. The densities of the rubber specimens at this temperature were measured by the method of hydrostatic weighings. The volume of the dilatometer up to the level of the mercury in the capillary at this temperature was obtained as the sum of the volumes of the mercury and the specimen. At any other temperature the volume up to the same point on the capillary was found from the known expansivity of Pyrex glass. The volume of the dilatometer up to any other point on the capillary could then be calculated from the calibration of the capillary. The volume of the specimen corresponding to each observation was obtained by subtracting from this volume the volume of the mercury at the temperature of the observation.

After the specimens and dilatometers had been prepared, they were usually placed in a stirred bath of about 6 liters of alcohol cooled by solid carbon dioxide to a temperature of about $-39^{\circ} \mathrm{C}$, an approximate lower limit set by the freezing of the mercury. Observations of the height of the mercury in the capillary were made as the temperature was raised to $+55^{\circ} \mathrm{C}$ at a rate of the order of 0.5 degree per minute. At the lower temperatures the bath was warmed at about this rate by the heat from its surroundings. Beginning at about $-10^{\circ} \mathrm{C}$, additional heat was furnished by means of a knife-type immersion heater controlled by a variable ratio autotransformer. The alcohol was usually replaced with water for measurements above room temperature. In this manner the volume-temperature relation of the amorphous rubber was obtained. This relation, which is linear over a considerable range of temperature, will be described and discussed in greater detail later in connection with the melting of crystalline rubber.

It was found in preliminary experiments that at a heating rate of 0.5 degree per minute or less no observable differences from the equilibrium values of the volume could be noted. At a heating rate of about 1 degree per minute the apparent volume lagged behind the 
equilibrium value by an amount equivalent to about 1 degree. At a heating rate of about 2 degrees per minute, the lag was about 2 degrees.

The dilatometers were next placed in a small unstirred alcohol bath in a refrigerator at the temperature at which it was desired to crystallize the rubber. Observations of the height of the liquid in the capillary tube were made periodically and usually continued until no further volume change could be noted.

When it was observed in this manner that the rate of crystallization had become inappreciable, the specimens were placed in the stirred bath of alcohol cooled by solid carbon dioxide to a temperature of about $-39^{\circ} \mathrm{C}$. Observations of the volume were made as before, as the temperature was raised, and the volume-temperature relation of the crystalline rubber was obtained.

In a number of cases, to be described in detail later, there were deviations from this standard procedure for the purpose of studying the effect of varying some of the experimental conditions, or because the importance of some of the exact conditions was not realized at the time the experiment was performed.

\section{EXPERIMENTAL RESULTS}

\section{RATE OF CRYSTALLIZATION}

When crystallization was carried out according to the procedure just described it was found that the rate was very low at first, increased to a maximum, and decreased to a negligible value. The volume-time relation at constant temperature thus has the sigmoid shape which has previously been given $[5,8,69]$ for crystallization near $0^{\circ} \mathrm{C}$. Figure 1 shows two families of such curves, one for crystallizing temperatures of $-22^{\circ} \mathrm{C}$ and above, and the other for $-22^{\circ} \mathrm{C}$ and below.

As the volume is changing very slowly in the final stages, a determination of the time required for completion is somewhat uncertain. The time required for one-half the total volume change is much more precisely determinable since the curves are usually steepest near this point. The time required for half the volume change has been measured at a number of different temperatures. The reciprocal of this time, it can be readily seen, is a measure of the average rate of crystallization during the first half of the process. It is plotted as a function of temperature in figure 2 .

\section{MELTING OF CRYSTALLIZED RUBBER}

When the volume-temperature relation of crystalline rubber is investigated, as already described, curves of the type shown in figure 3 are obtained for increasing temperatures.

It can readily be seen that melting of the crystals occurs over a range of temperature and that the range is markedly dependent on the temperature at which crystallization has occurred [7]. The temperature corresponding to the beginning of melting is that at which the volume begins to deviate from the curve representing the normal thermal expansion of crystalline rubber. Over the range of temperatures under consideration here the normal expansion curve is 


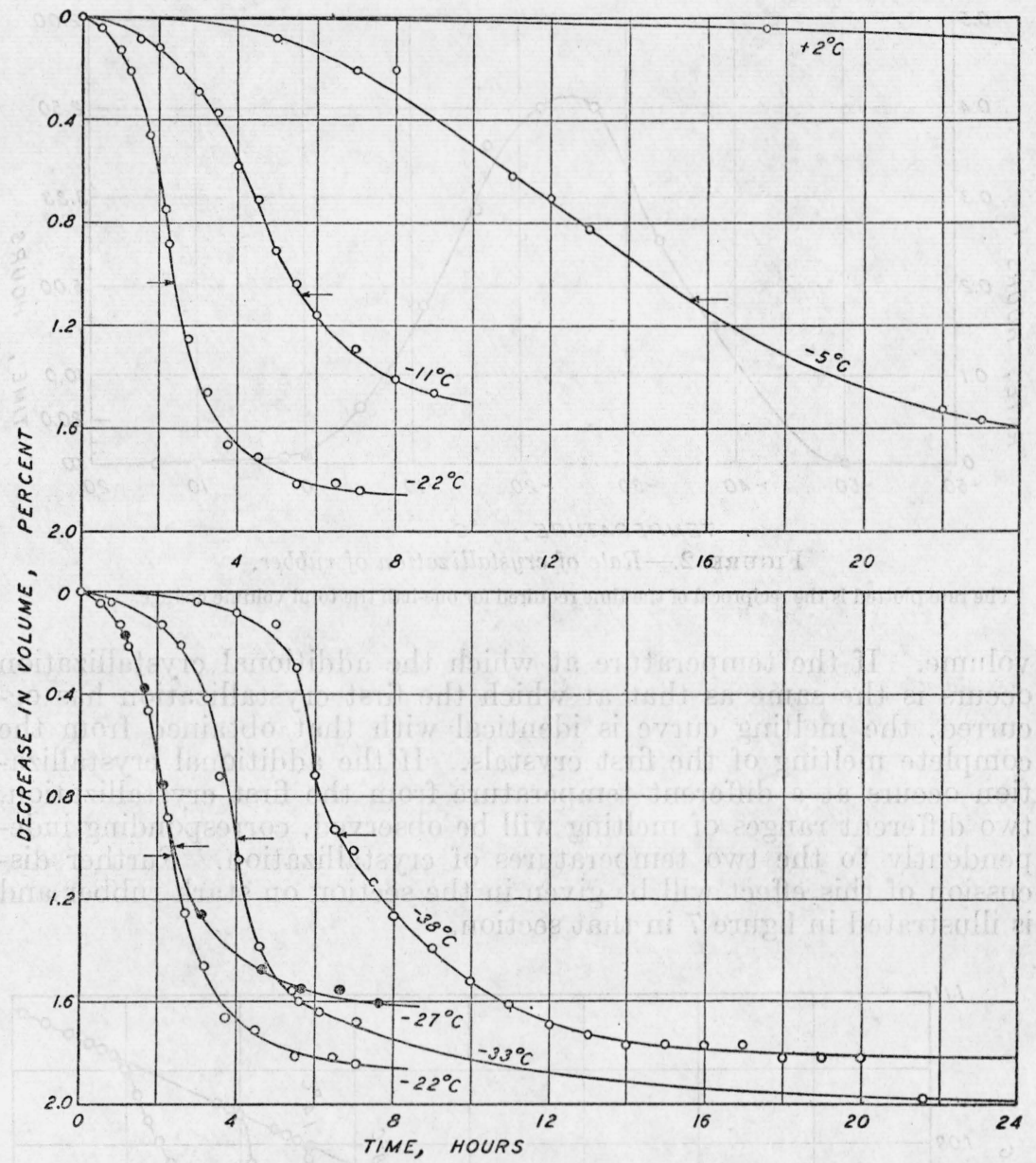

Figure 1.-Crystallization of rubber at different temperatures as indicated by decrease in volume.

The arrows indicate the estimated values for half the total decrease of volume at each temperature.

linear, and the temperature at which deviation begins to occur can be located within about one-half degree. Similarly, melting is complete when the volume again reaches the nearly linear curve that represents the volume-temperature relation of amorphous rubber, and which was evaluated earlier.

There was found to be no evidence of any time lag, or delay, in melting of the crystals after the establishment of thermal equilibrium. For example, at any constant temperature in the melting range the volume was never observed to increase with time. In this range if the temperature is lowered, the volume-temperature relation is observed to be linear and intermediate between the amorphous and crystalline volumes. Rubber in the partially melted state, however, can undergo additional crystallization, with a resulting decrease of 


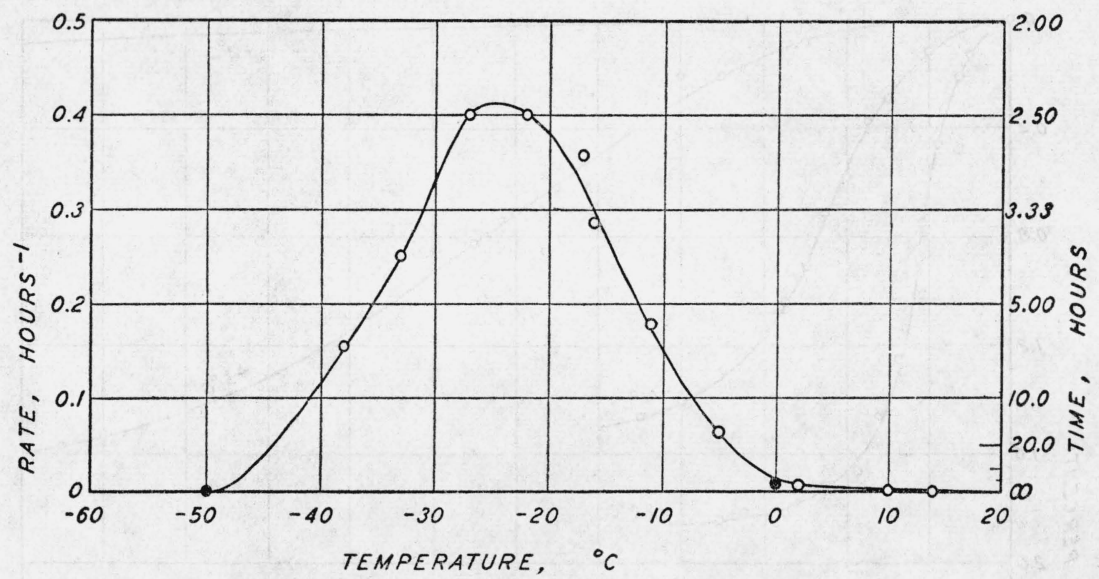

FigURE 2.-Rate of crystallization of rubber.

The rate plotted is the reciprocal of the time required for one-half the total volume change.

volume. If the temperature at which the additional crystallization occurs is the same as that at which the first crystallization has occurred, the melting curve is identical with that obtained from the complete melting of the first crystals. If the additional crystallization occurs at a different temperature from the first crystallization, two different ranges of melting will be observed, corresponding independently to the two temperatures of crystallization. Further discussion of this effect will be given in the section on stark rubber and is illustrated in figure 7 in that section.

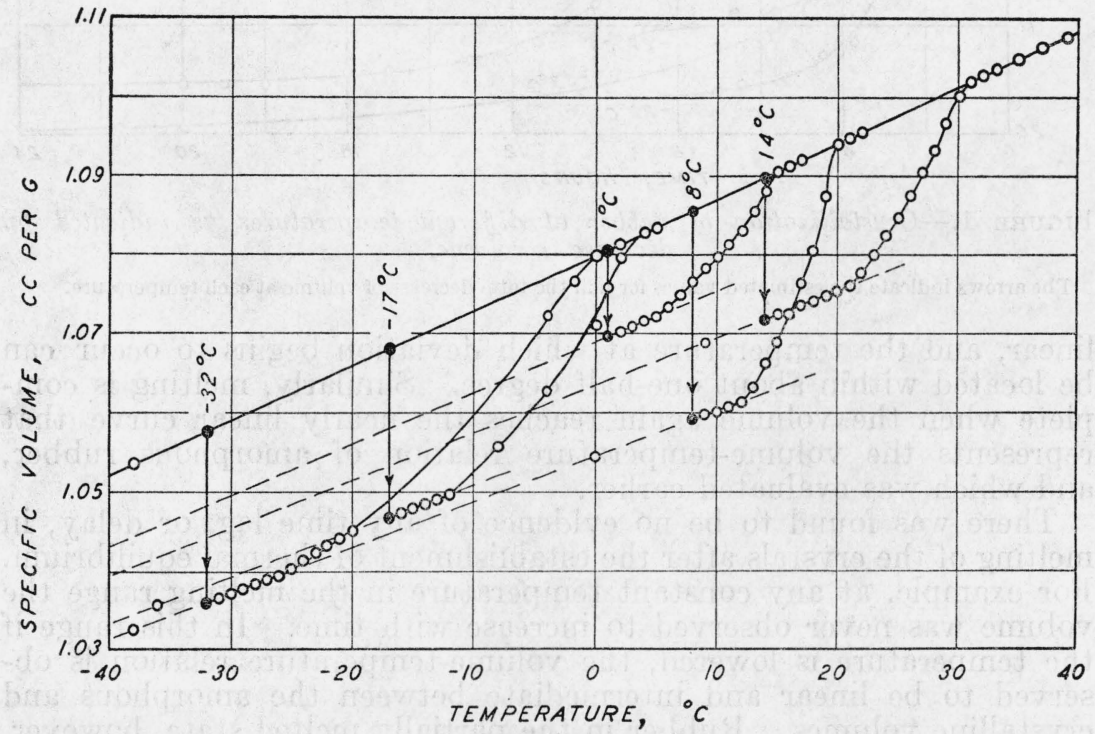

FIGURE 3.-Crystallization of rubber at different temperatures and subsequent melting. The change of specific volume on crystallization is indicated by the vertical lines joining the dark circles. 
The additional crystallization possible in partially melted rubber mentioned in the preceding paragraph is considered in more detail in the section dealing with recrystallization. At this stage, however, it should be pointed out that the phenomenon may give rise to difficulty in determining the upper end of the melting range itself.

The rate of crystallization at certain temperatures was sufficiently great to permit significant recrystallization during the time that the temperature was being raised through the melting range of the original crystals. As the recrystallization took place at a higher temperature than the original crystallization, the new crystals melted at a higher temperature than the original crystals, and the apparent upper end of the melting range was displaced upward by an amount that depended on the rate of temperature rise during melting.

When the initial crystallization occurred below $0^{\circ} \mathrm{C}$, therefore, the upper end of the melting range was determined from a series of experiments at each temperature of crystallization. A stirred bath was adjusted to the approximate temperature of the upper end of the melting range. The dilatometer was then removed from the bath in which the original crystallization had been taking place and plunged into the stirred bath. The volume of the specimen increased because of both thermal expansion and the melting of the crystals. In less than 5 minutes, a reasonable time for the establishment of temperature equilibrium, the volume became constant. After an interval of time, the volume began to decrease because of recrystallization at the temperature of the stirred bath.

If the value of the volume when temperature equilibrium had become established and before observable recrystallization had occurred was the same as that originally observed for amorphous rubber at the corresponding temperature, it was concluded that the temperature of the stirred bath was at or above the upper end of the melting range. If the volume at equilibrium was less than that of the amorphous rubber at that temperature, the conclusion was drawn that the melting was incomplete and that the temperature of the bath was below the upper end of the melting range. As might be expected, the volume at equilibrium was never found to be greater than the volume of the amorphous rubber. A series of experiments of this sort served to locate the upper end of the melting range corresponding to a single temperature of original crystallization, and an additional series was required for each other temperature.

If the initial crystallization occurred at $0^{\circ} \mathrm{C}$ or above, the rate of recrystallization during melting was found to be so small as not to be significant during the time the specimen was in the melting range when the usual heating rates were employed. At these temperatures the range was of the order of 10 degrees or less, and the time required to cover the range was usually between 20 and 30 minutes. The upper end of the melting range was determined from curves of the type shown in figure 3 for all cases where the initial crystallization was at $0^{\circ} \mathrm{C}$ or above.

The results of a number of individual experiments of this sort are plotted in figure 4 , which shows the melting range as a function of the temperature of crystallization.

In one series of experiments a specimen was successively crystallized and melted 16 times. After each melting the temperature was raised 


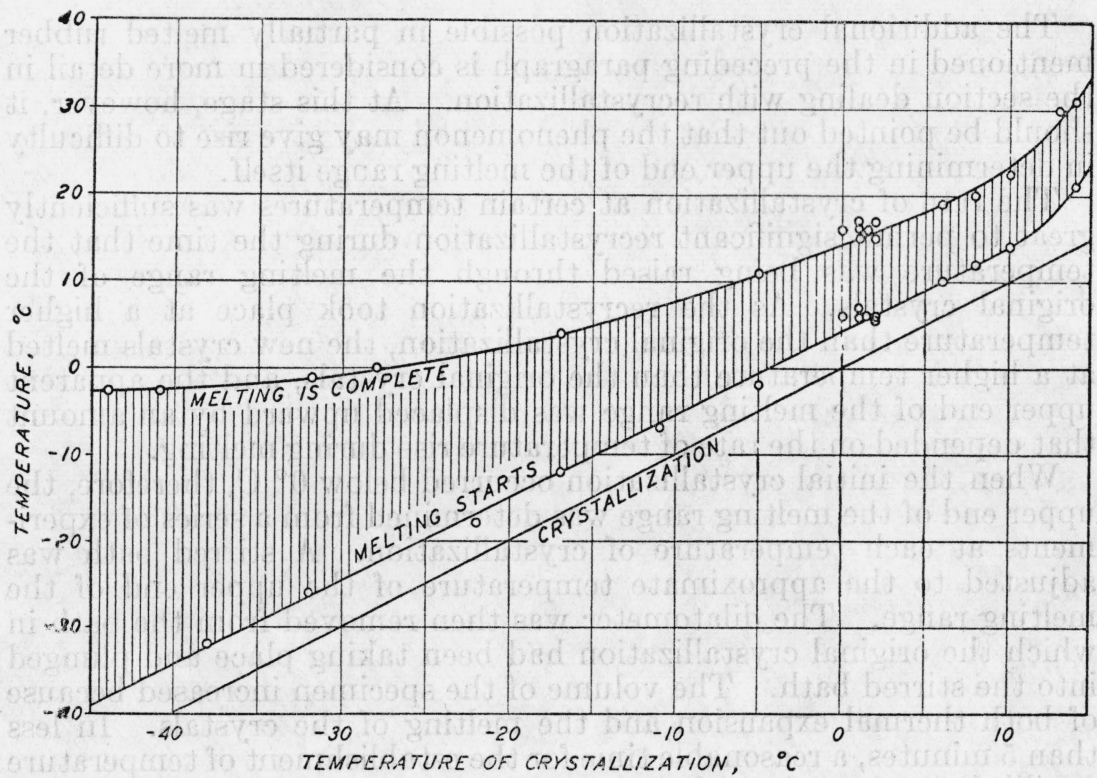
FIGURE 4.-Melting range of crystalline rubber as a function of the temperature

The lowest line shows the crystallization temperature also as ordinate for easier comparison with the range of melting.

by different amounts varying from 1 to 40 degrees above the end of the melting range. In all cases, the same melting range was obtained on subsequent crystallization at a fixed temperature.

\section{PARTIAL CRYSTALLIZATION}

The melting range of partially crystallized rubber has been found to be the same as that obtained when the crystallization is more nearly complete. Data regarding this point were obtained from a series of experiments in which the specimen was kept at $2^{\circ} \mathrm{C}$ for different lengths of time, and the melting range of the resulting crystals then measured. In the first experiment, after 20 days of crystallization the volume decrease amounted to 2.7 percent. In the second experiment, crystallization was interrupted at the end of 9 days when the volume change amounted to only 1.0 percent (or 37 percent of the volume change in the first experiment). In the third experiment, by interruption of the crystallization after 1 day the volume change was limited to 0.085 percent (or 3.1 percent of that in the first experiment).

The melting range in all three cases was $6^{\circ}$ to $16^{\circ}$, within the accuracy of determination. On the basis of these experiments, the crystallization in some cases was not carried completely to the point where the volume had ceased to change at a significant rate. Cases of this sort will be observed in figure 3 . 


\section{RECRYSTALLIZATION OF RUBBER}

It will be noted that in the cases previously described the specimens were heated to at least $55^{\circ} \mathrm{C}$ immediately before crystallization. The purpose of this heating was to destroy centers of crystallization that might have been persisting from previous crystallizations, and that would have altered the rate of crystallization. A study of the rate of recrystallization when the specimen had not received such heating will now be described.

The preliminary crystallization was first carried out overnight at $-33^{\circ} \mathrm{C}$ according to the standard procedure already described. The specimen was then plunged into a bath held at $0^{\circ} \mathrm{C}$, and observa-

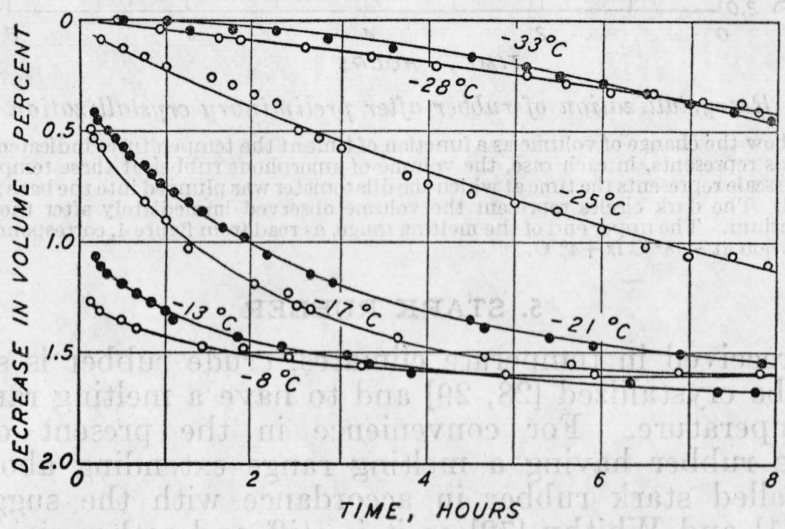

FIgURE 5.-Recrystallization of rubber at $0^{\circ} \mathrm{C}$.

The curves show the change of volume as a function of time, after preliminary crystallizations at the fixed temperatures indicated on the curves. The zero on the ordinate axis represents the volume of amorphous rubber at $0^{\circ} \mathrm{C}$. The zero on the time scale represents the time at which the dilatometer was plunged into the bath at $0^{\circ} \mathrm{C}$. Observations taken in the first 5 minutes, before the attainment of temperature equilibrium, are omitted. The upper ends of the melting ranges, as read from figure 4, corresponding to the different temperatures of preliminary crystallization are $-2^{\circ},-1^{\circ},+1^{\circ},+2^{\circ},+4^{\circ},+6^{\circ}$, and $+9^{\circ} \mathrm{C}$, respectively.

tions were made of the change of volume with time. It will be noted from figure 4 that the melting of crystals formed at $-33^{\circ} \mathrm{C}$ is complete below $0^{\circ} \mathrm{C}$. At first, there was a volume increase due to thermal expansion and to the melting of the crystals. This change was found to be complete within about 5 minutes, a reasonable time for the establishment of thermal equilibrium. After an interval of time there was a volume decrease due to recrystallization at $0^{\circ}$. The whole procedure was repeated with the preliminary crystallization occurring at $-28^{\circ},-25^{\circ},-21^{\circ},-17^{\circ},-13^{\circ}$, and $-8^{\circ} \mathrm{C}$, respectively. The results are reproduced in figure 5 .

Very similar results were obtained when the conditions were altered so that the preliminary crystallization was carried out in each case at $-18^{\circ} \mathrm{C}$, and the recrystallization at temperatures of $-8^{\circ},-4^{\circ}, 0^{\circ}$, $+1^{\circ},+2^{\circ}$, and $+4^{\circ} \mathrm{C}$, respectively. The results are shown in figure 6. The significance of these results is discussed in a later section. 


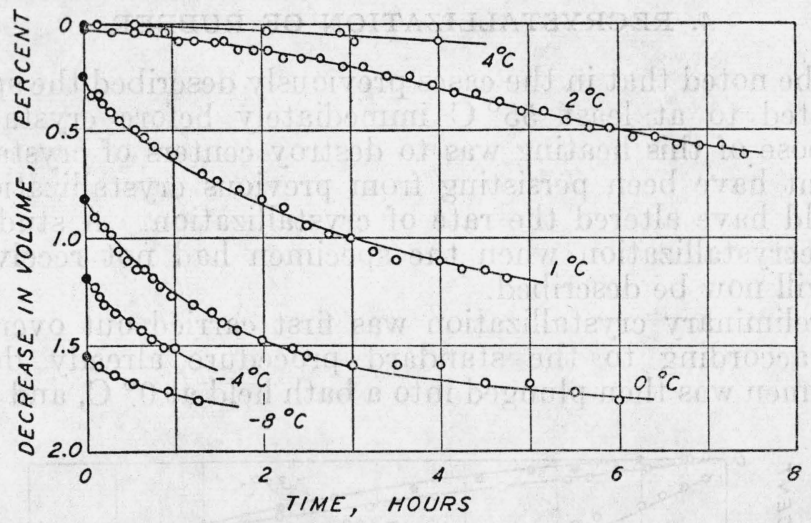

FIGURE 6.-Recrystallization of rubber after preliminary crystallization at $-18^{\circ} \mathrm{C}$.

The curves show the change of volume as a function of time at the temperatures indicated. The zero on the ordinate axis represents, in each case, the volume of amorphous rubber at these temperatures. The zero on the time scale represents the time at which the dilatometer was plunged into the bath at the temperatures indicated. The dark circles represent the volume observed immediately after the attainment of thermal equilibrium. The upper end of the melting range, as read from figure 4, corresponding to preliminary crystallization at $-18^{\circ} \mathrm{C}$ is $+4^{\circ} \mathrm{C}$.

\section{STARK RUBBER}

When received in temperate climates, crude rubber is sometimes found to be crystallized $[28,29]$ and to have a melting range above room temperature. For convenience in the present discussion, crystalline rubber having a melting range extending above $25^{\circ} \mathrm{C}$ will be called stark rubber in accordance with the suggestion of Pickles [51] and Whitby [72] as it is stiff and rather rigid at room temperature. The use of such a term is not intended to imply any essential fundamental difference between stark rubber and that melting at lower temperatures. It is to be presumed, on the basis of figure 4, that during the formation of the crystals in stark-rubber conditions were such that the stark rubber was crystallized at temperatures higher than about $10^{\circ} \mathrm{C}$. No cases, other than those in the present paper, seem to have been reported in which the temperature of crystallization was measured (or even estimated, within 10 degrees centigrade) during the formation of stark rubber.

One sample of stark rubber, for which the authors are indebted to H. I. Cramer, formerly professor at the University of Akron, was found to have a melting range from about $32^{\circ}$ to $39^{\circ} \mathrm{C}$. When specimens of this stark rubber were placed in a dilatometer and held at a temperature of about $1^{\circ} \mathrm{C}$ for 48 days considerable additional crystallization occurred, most of it within the first few days. When the specimens were melted in the usual manner the curves shown in figure 7 were obtained. The line between $16^{\circ}$ and $32^{\circ} \mathrm{C}$ passes through the points obtained before the stark rubber was held at $1^{\circ} \mathrm{C}$ for the additional crystallization.

In another experiment, one end of a strip of stark rubber was immersed in water at $50^{\circ} \mathrm{C}$ for a few minutes. The lower end was thereby melted, whereas the upper end remained in the stark condition. When the whole strip was placed in a refrigerator at $1^{\circ} \mathrm{C}$ for several weeks the lower end crystallized and could not be distin- 


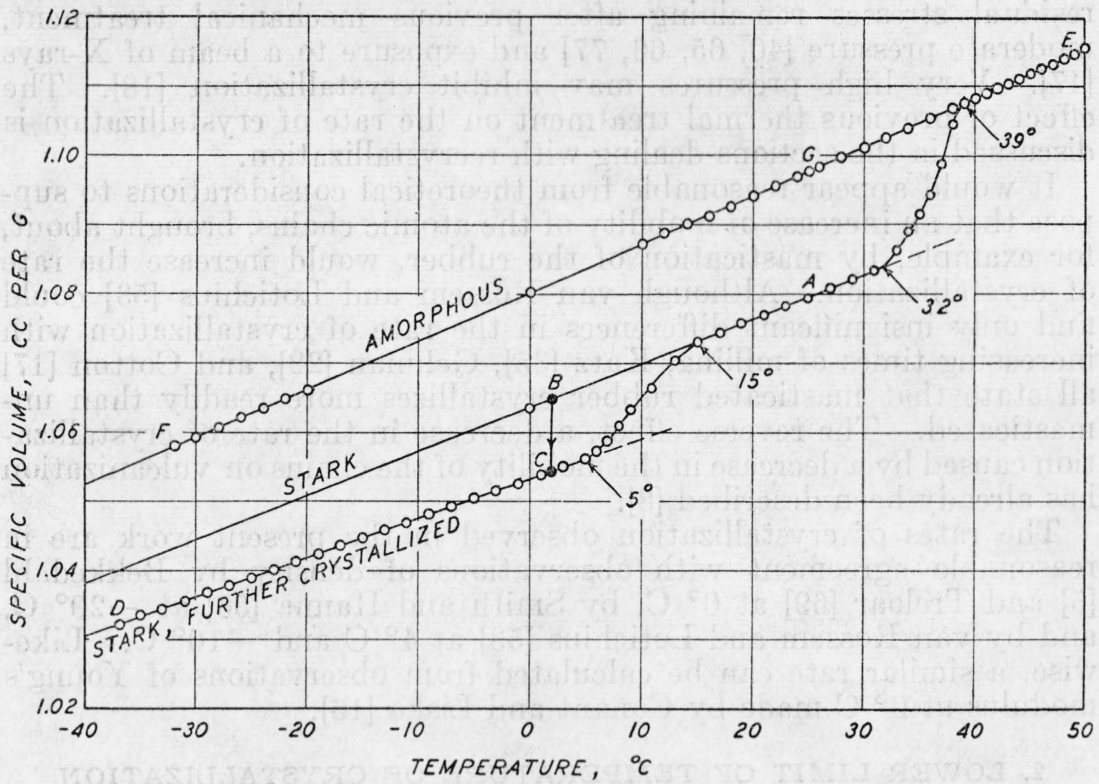

FIGURE 7.-Further crystallization and melting of a sample of stark rubber.

The specific volume of the sample as received is shown at $A$. It was cooled to $B$, where further crystallization occurred, reducing the specific volume to $C$. After cooling the sample to $D$, the temperature was raised to $E$. The temperature was lowered to $F$, and then raised to room temperature at $G$.

guished by visual or tactual observation from the upper end. However, when the strip was allowed to come to room temperature the crystals in the lower end melted, as would be expected from figure 4, whereas the upper end remained stark.

\section{DISCUSSION OF RESULTS}

\section{RATE OF CRYSTALLIZATION}

It should be recognized that the measurements reported here regarding the rate of crystallization were all made on not more than two or three specimens of smoked sheet that had been heated to $55^{\circ}$ $\mathrm{C}$ immediately before the crystallization. The conditions of preparation of the rubber from the latex undoubtedly have a considerable influence on the rate of crystallization [42]. Uncoagulated latex showed no volume change when kept in a dilatometer at $2^{\circ} \mathrm{C}$ over a period of several months. This behavior confirmed previous observations in this laboratory [5]. Likewise, qualitative observation showed that crystallization was extremely slow in a sheet of evaporated latex. In this case crystallization appeared to take place most readily in certain regions. This effect is similar to the "patchy crystallization" described by Treloar [69], who reported that visual observations on a sample of smoked sheet showed that neighboring portions crystallized at widely different rates. No attempt was made in the present work to investigate the exact reasons for such differences. Various factors that have been reported to increase the rate of crystallization are 
residual stresses remaining after previous mechanical treatment, moderate pressure $[40,65,66,77]$ and exposure to a beam of X-rays [47]. Very high pressures may inhibit crystallization [18]. The effect of previous thermal treatment on the rate of crystallization is discussed in the sections dealing with recrystallization.

It would appear reasonable from theoretical considerations to suppose that an increase of mobility of the atomic chains, brought about, for example, by mastication of the rubber, would increase the rate of crystallization. Although van Rossem and Lotichius [53] could find only insignificant differences in the rate of crystallization with increasing times of milling, Katz [35], Gehman [22], and Cotton [17] all state that masticated rubber crystallizes more readily than unmasticated. The reverse effect, a decrease in the rate of crystallization caused by a decrease in the mobility of the chains on vulcanization has already been described [8].

The rates of crystallization observed in the present work are in reasonable agreement with observations of density by Bekkedahl [5] and Treloar [69] at $0^{\circ} \mathrm{C}$, by Smith and Hanna [56] at $-20^{\circ} \mathrm{C}$, and by van Rossem and Lotichius [53] at $4^{\circ} \mathrm{C}$ and $-10^{\circ} \mathrm{C}$. Likewise, a similar rate can be calculated from observations of Young's modulus at $0^{\circ} \mathrm{C}$ made by Conant and Liska [16].

\section{LOWER LIMIT OF TEMPERATURE OF CRYSTALLIZATION}

It has been recognized for some years that rubber does not crystallize at extremely low temperatures. No crystallization was evident in a specimen [5] cooled at $-259^{\circ} \mathrm{C}$, or in another [52] held at $-199^{\circ}$ $\mathrm{C}$ for 8 days. Other specimens $[5,49]$ were kept between $-50^{\circ} \mathrm{C}$ and $-78^{\circ} \mathrm{C}$ for 3 weeks without the occurrence of crystallization but did crystallize at $-35^{\circ} \mathrm{C}$ and above. The present work serves to locate more definitely the lower limit of temperature at which crystallization is possible as about $-50^{\circ} \mathrm{C}$. Figure 2 shows that the rate of crystallization has become negligible below this temperature. Here the mobility is presumably insufficient to permit the orientation necessary for the formation of crystals. The supercooling of rubber is similar in this respect to that of selenium [45], sulfur, and many organic liquids.

\section{UPPER LIMIT OF TEMPERATURE OF CRYSTALLIZATION}

Crystallization has not been reported at the room temperatures (usually above $20^{\circ} \mathrm{C}$ ) normally maintained in American laboratories. No evidence of it was noted in the present investigation when dilatometers were kept at room temperature over a period of a year or more. In European laboratories, however, where the temperatures are frequently near $15^{\circ} \mathrm{C}$, the crystallization of rubber on storage has been noted on a number of occasions [38, 44, 46, 52]. Cotton [17], for example, states: "When smoked sheet and crepe rubber have been in storage for some time, they gradually harden and assume a frozen condition. This is due to crystallization." In the present work the highest temperature at which crystallization was observed was $14^{\circ} \mathrm{C}$. At this temperature, under the experimental conditions described here, the time required for crystallization is of the order of years. Crystallization at this temperature was continuing at an 
approximately constant rate when the experiment was discontinued after 289 days.

The crystallization observed in European laboratories appears to occur at a more rapid rate than this. Quite probably temperatures lower than $15^{\circ} \mathrm{C}$ during the night initiated the crystallization, and the crystals then formed were not melted near $15^{\circ} \mathrm{C}$ during the day.

It is possible to increase the rate of crystallization by varying the previous thermal or mechanical treatment of the specimen, and thereby forming more centers of crystallization. Consequently, it is likely that the upper limit of temperature of crystallization shown in figure 2 may be raised somewhat by the proper previous treatment of the rubber.

\section{TEMPERATURE AT WHICH CRYSTALLIZATION IS MOST RAPID}

The rate of crystallization was found to be a maximum at a temperature near $-25^{\circ} \mathrm{C}$, as can be seen in figure 2 . In the production of the form of raw rubber known as "cut sheet" or "patent rubber" [27] developed in Europe many years ago, rubber is crystallized so that it can be cut into sheets. The rubber is often held at a temperature of about $-5^{\circ}$ for a few days in order to bring about the crystallization. More recent books $[9,64]$ state that the rubber should be held between $-5^{\circ}$ and $-10^{\circ} \mathrm{C}$ for at least 6 days. No quantitative study of the rates at different temperatures, as in the present work, seems to have been reported previously.

\section{MAGNITUDE OF THE VOLUME CHANGE ON CRYSTALLIZATION}

The magnitude of the percentage decrease of volume on crystallization can be noted from curves of the type shown in figure 1. The actual specific volume of the amorphous rubber varies with temperature, and can be read from curves like those in figure 3 . The decrease of specific volume on crystallization is of course found to be the same as the increase of specific volume on subsequent melting. However, it might be pointed out that the percentage decrease of volume is not quite the same as the subsequent percentage increase of volume, as they are fractions of different quantities. Furthermore, any comparisons must be made at the same temperature.

In most cases in the present work, the decreases of volume on crystallization were found to lie between 2.0 and 2.7 percent. Repeated crystallizations of the same specimen under conditions that were thought to be identical did not always lead to the same volume changes. It seems possible that such variations are statistical fluctuations occasioned by the growth of crystals from different centers in different cases. There was an even greater variation in the decreases of volume when different specimens were studied, but in almost all cases the values lay within the limits given. The exact value, within these limits, seems to depend upon factors that were not under control.

Values for this quantity, calculated from measurements of density or specific gravity reported by previous workers $[4,5,8,14,19,31$, $39,53,55,56,72]$ generally lie within the same limits, although a few are somewhat lower. Holt and McPherson [32] found a volume 
change of about 1.85 percent on stretching a specimen of vulcanized rubber to an elongation of 700 percent at $25^{\circ} \mathrm{C}$. Treloar [69], by stretching unvulcanized rubber at $0^{\circ} \mathrm{C}$, observed a volume decrease of over 3 percent, the highest value reported. With unstretched pale crepe he found a volume decrease of 2.3 percent on crystallization at $0^{\circ} \mathrm{C}$.

Observations made in the course of the present work furnish no data from which conclusions may be drawn as to the relative amounts of crystalline and amorphous material in a specimen.

Field $[21,24]$ has recently conducted X-ray studies of the proportion of crystalline and amorphous components in stretched rubber, and concludes that under favorable conditions about 80 percent of the material is in the crystalline state, in agreement with an earlier study by Meyer and Mark 143]. This value is considerably higher than those estimated by Parks [50] and Wildschut [73] by other methods. If reliance is to be placed on X-ray values, it would be very desirable to conduct several parallel studies of crystallization by means of $\mathrm{X}$-rays and by means of observations of volume change. In this manner the relation between the percentage decrease of volume and percentage of crystalline material could be established.

\section{MELTING OF CRYSTALLIZED RUBBER}

The melting of the crystalline rubber is very much dependent on the temperature at which the crystals have been formed, as can be seen from figures 3 and 4 . This conclusion seemed so surprising that it was made the subject of a preliminary communication [7] based upon only a part of the data reported in the present paper.

It can be seen that the higher the temperature of crystallization the higher are the temperatures at which both the beginning and the ending of the melting occur. The beginning of melting occurs at a temperature of from 4 to 7 degrees above that at which the crystals have been formed. For all temperatures of crystallization below about $-35^{\circ} \mathrm{C}$, the temperature at which melting is complete is about $-2^{\circ} \mathrm{C}$.

The range of melting becomes narrower the higher the temperature of crystallization, up to about $0^{\circ} \mathrm{C}$; for crystals formed at temperatures between $0^{\circ}$ and $14^{\circ} \mathrm{C}$, the range of melting is about 10 degrees; for crystallization at higher temperatures no direct observations are available, but the range is probably narrower, as it appears that stark rubber has a somewhat narrower range of melting the higher the mean temperature of the range.

The results presented here undoubtedly explain many previously reported discrepancies in the temperatures of melting of crystalline rubber. Unfortunately, in only a few cases have previous workers specified the temperature at which crystallization occurred. The variations in the melting have sometimes been thought to be connected with the variety of rubber or the experimental method. In most cases no explanation at all was attempted. Table 1 presents the results of measurements of the melting temperatures of crystalline rubber, as reported by previous observers. In those instances in which the temperature of crystallization was reported, the only pronounced deviations from the results of figure 4 are in the few instances where the crystals were formed from solution rather than from the bulk material. 
TABLE 1.-Melting temperatures of crystalline rubber previously reported

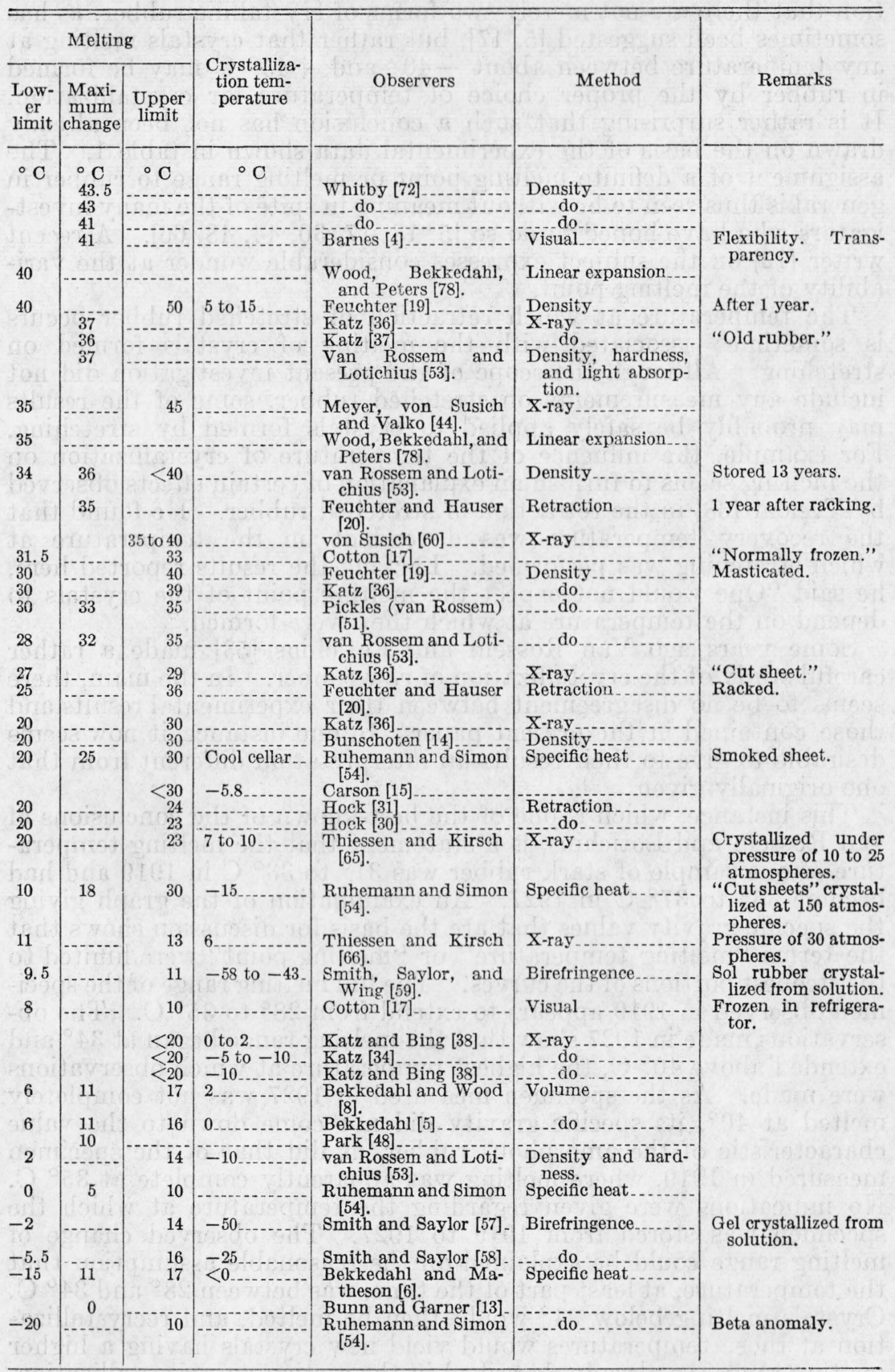


A study of table 1 confirms the conclusion of the present investigation that there are not merely two forms of crystalline rubber, as has sometimes been suggested [5, 17], but rather that crystals melting at any temperature between about $-40^{\circ}$ and $+45^{\circ} \mathrm{C}$ may be formed in rubber by the proper choice of temperature for crystallization. It is rather surprising that such a conclusion has not been already drawn on the basis of the experimental data shown in table 1. The assignment of a definite melting point or melting range to rubber in general is thus seen to be without meaning in spite of the many investigators who have hoped to do so $[5,13,17,30,44,48,66]$. A recent writer [12] on the subject expresses considerable wonder at the variability of the melting point.

The temperature at which retraction of stretched rubber occurs is sometimes associated with the melting of crystals formed on stretching. Although the scope of the present investigation did not include any measurements on stretched rubber, some of the results may probably be safely applied to crystals formed by stretching. For example, the influence of the temperature of crystallization on the melting seems to furnish an explanation of certain effects observed by Treloar [68] in the retraction of stretched rubber. He found that the recovery temperature was dependent on the temperature at which stretching was performed. Lacking the results reported here, he said "One would not expect the melting point of the crystals to depend on the temperature at which they were formed."

Some years ago Van Rossem and Lotichius [53] made a rather careful study of the crystallization of raw rubber. In the main, there seems to be no disagreement between their experimental results and those contained in the present paper. In one instance, it now seems desirable to give to their results an interpretation different from that one originally given.

This instance, which is one of the best-known of the conclusions of van Rossem and Lotichius, is a statement that the melting temperature of one sample of stark rubber was $31^{\circ}$ to $33^{\circ} \mathrm{C}$ in 1919 and had become $35^{\circ}$ to $37^{\circ} \mathrm{C}$ in 1927. An examination of the graph giving the specific gravity values that are the basis for discussion shows that the terms "melting temperature" or "melting point" were limited to the steepest portions of the curves. The full melting range of the specimen observed in 1919 appears to extend from $28^{\circ}$ to $35^{\circ} \mathrm{C}$. The observations made in 1927 show that the melting range began at $34^{\circ}$ and extended above $40^{\circ} \mathrm{C}$, the highest temperature at which observations were made. As the specimen measured in 1927 was not completely melted at $40^{\circ}$, its specific gravity did not come down to the value characteristic of the amorphous rubber, as did that of the specimen measured in 1919 , where melting was apparently completelat $35^{\circ} \mathrm{C}$. No indications were given regarding the temperature at which the specimen was stored from 1919 to 1927 . The observed change of melting range could be explained on the reasonable assumption that the temperature, at least part of the time, was between $28^{\circ}$ and $34^{\circ} \mathrm{C}$. Crystals melting below $34^{\circ}$ would then be melted, and recrystallization at those temperatures wovld yield new crystals having a higher melting range, as already described in the section on recrystallization.

Thus there seems to be no assurance that van Rossem and Lotichius would have found a rise in the meeting range during storage at a con- 
stant temperature below $28^{\circ} \mathrm{C}$. No such rise was observed in the course of the present work. The actual phenomena observed by van Rossem and Lotichius can then be explained in terms of the results of the present paper, without recourse to speculative assumptions of changes in crystal size or polymerization.

The considerations developed in the present work on the melting of crystalline rubber have already been applied [75] to explain results obtained by Ruhemann and Simon [54] in measurements of specific heat. It has been pointed out that the beta-anomaly they observed can be explained as a phenomenon of crystallization under the particular conditions of their experiments, without the assumption of an anomaly characteristic of rubber in general. The volumetemperature graphs they give for rising temperatures are of the same form as those obtained in the present work when the rate of temperature rise was slow enough to permit recrystallization and subsequent melting at higher temperatures.

\section{RECRYSTALLIZATION}

A number of interesting conclusions may be drawn from the experiments on recrystallization illustrated in figures 5 and 6 . In the first place, the rate of crystallization at a given temperature is much greater than in the instances previously discussed, where the standard procedure called for heating to at least $55^{\circ} \mathrm{C}$ before each crystallization to destroy possible centers of crystallization. An examination of figure 1 shows that at $2^{\circ} \mathrm{C}$ after such treatment the change of volume in the first 10 hours is about 0.05 percent. On the scales used in figures 5 and 6 such a change would hardly be perceptible, and the experimental points would lie on an almost horizontal line through the origin. In the second place, the effects of the preliminary crystallization in increasing the rate of subsequent crystallization extend at least several degrees above the upper end of the melting range. For example, it is clear from figure 6 that the melting range does not extend above $4^{\circ} \mathrm{C}$, as the initial ordinate is zero for the recrystallization at $4^{\circ} \mathrm{C}$. The rate of recrystallization at $4^{\circ} \mathrm{C}$ is seen to be of appreciable magnitude in comparison with the much lower rate that is observed when the centers of crystallization are destroyed by previous heating to $55^{\circ} \mathrm{C}$.

The selection of a temperature of $55^{\circ} \mathrm{C}$ as being sufficient to destroy centers of crystallization was based on the fact that it was 5 or 10 degrees above the highest temperature at which any crystals have been reported in unstretched rubber, as noted in table 1. In numerous experiments no evidence of any effect of previous thermal history was found persisting in any sample after heating it to $55^{\circ} \mathrm{C}$.

Attention should be called to the two different types of crystallization curves shown in figures 5 and 6 . At temperatures below the upper end of the melting range, the rate of crystallization has its largest value at the beginning and decreases with increasing time. At temperatures above the upper end of the melting range, the rate of crystallization is small at the beginning, increases with time to a maximum, and, when observations are carried out over a sufficiently long period, decreases again to a negligible value. The latter curves are thus of the sigmoid type shown in figure 1. One can therefore 
conclude from figure 5 alone that the end of the melting range would be at $0^{\circ} \mathrm{C}$ following crystallization at a temperature between $-25^{\circ}$ and $-28^{\circ} \mathrm{C}$. From figure 4 this temperature is read as $-28^{\circ} \mathrm{C}$.

In terms of the usual conceptions of crystal growth, it is possible to give a simple explanation of the difference between the two types of curves. In accordance with the ideas of Tammann and others $[3,23,25,33,61,62,71]$, a crystal can be initiated only at certain centers, or nuclei. The crystal, once initiated, grows from the center at a characteristic rate, called the linear crystallization velocity, until the available crystallizable material between it and the next crystal is exhausted.

In the first instance, where crystallization represents merely further growth of crystals already present, no additional centers of crystallization are necessary. The rate of crystallization as measured by volume change is therefore a maximum at the beginning and decreases because of the exhaustion of crystallizable material. In the second instance, crystallization at the beginning is slow because of the lack of a sufficient number of centers from wbich crystals may grow. Crystals start from the available centers, and more centers are formed as time goes on $[3,26,76]$. Thus the rate of crystallization increases at first, reaching a maximum, and then decreases again with the exhaustion of crystallizable material.

At temperatures immediately above the upper end of the melting range there remains of course no crystalline material. However, centers of crystallization must persist at least several degrees above the end of the melting range, because the rate of recrystallization at these temperatures, as shown in figure 7, is much greater than is the case when the centers of crystallization are destroyed by heating them to $55^{\circ} \mathrm{C}$.

\section{NATURE OF THE CRYSTALS}

The nature of the crystalline regions in long-chain high polymers has been the subject of considerable discussion in recent years. Alfrey and Mark [1, 2, 41], Bunn [10, 11, 12], Treloar [70], and Wood [76] have summarized some of the ideas. It seems generally agreed, for instance, that the structural units of the crystallites are not whole molecules but rather kinetic units that are segments of chains. Consequently, a single chain may contain segments that are units in two or more different crystallites, joined by segments that are to be regarded as part of the amorphous material.

The scope of the present paper does not include any attempt to extend the detailed conception of the nature of the crystals on the basis of the results obtained here. It has already been pointed out elsewhere [76] that these results cast grave doubts on the acceptibility of several theories proposed to account for the existence of a range of melting. The field is still open for a theory that will logically and satisfactorily explain two experimental observations reported here: (1) that the range of melting is not dependent on the extent of crystallization, and (2) that it is definitely determined by the temperature at which crystallization occurs.

Crystals of a lower-melting type can be formed and melted in a specimen already containing crystals of a higher-melting type, as shown in the experiments illustrated by figure 7. It is rather remark- 
able that the presence of crystals of the higher-melting type appears to have so little effect on the formation and melting of the lowermelting crystals. It does appear that the two types must compete for crystallizable material, as the total volume change does not exceed 3 percent in any case.

It cannot be emphasized too strongly that the sole important factor in determining the melting range is the temperature at which crystallization occurs. Other conditions may alter the rate of crystallization by a large factor or the volume change during crystallization, as already discussed, but the melting range remains the same. Even different degrees of vulcanization [8] do not alter the relation between melting range and temperature of crystallization. Thus the quantitative results depicted in figure 4 are regarded to be of much more general application than the other portions of the present investigation.

The experimental work described in this paper was performed between 1940 and 1942, but war activities prevented earlier publication, except for a preliminary note [7] on the change of melting range with temperature of crystallization.

\section{REFERENCES}

[1] T. Alfrey and H. Mark, "Phase transitions in rubber and their connection with the stress-strain curve, Rubber Chem. Tech. 14, 525 (1941).

[2] T. Alfrey and H. Mark, A statistical treatment of crystallization phenomena in high polymers, J. Phys. Chem. 46, 112 (1942); Rubber Chem. Tech. 15, $462(1942)$.

[3] M Avrami, Kinetics of phase change, J. Chem. Phys. 7, 1103 (1939); 8, 212 (1940); 9, 177 (1941).

[4] W. H. Barnes, Diffraction of X-rays by old specimens of "frozen" rubber Canadian J. Research 15, 156 (1937); Rubber Chem. Tech. 10, 462 (1937).

[5] N. Bekkedahl, Forms of rubber as indicated by temperature-volume relationship, J. Research NBS 13, 411 (1934) RP717; Rubber Chem. Tech. 8, 5 (1935).

[6] N. Bekkedahl and H. Matheson, Heat capacity, entropy, and free energy of rubber hydrocarbon, J. Research NBS 15, 503 (1935) RP844; Rubber Chem. Tech. 9, 264 (1936).

[7] N. Bekkedahl and L. A. Wood, Influence of the temperature of crystallization on the melting of crystalline rubber, J. Chem. Phys. 9, 193 (1941); Rubber Chem. Tech. 14, 544 (1941).

[8] N. Bekkedahl and L. A. Wood, Crystallization of vulcanized rubber, Ind. Eng. Chem. 33, 381 (1941); Rubber Chem. Tech. 14, 347 (1941).

[9] S. Boström, K. Lange, H. Schmidt, and P. Stöcklin, Kautschuk and verwandte Stoffe (Union Deutsche Verlagsgesellschaft Berlin Roth \& Co., Berlin, 1940).

[10] C. W. Bunn, Molecular structure and rubber-like elasticity. I. The crystal structure of beta gutta-percha, rubber, and polychloroprene, Proc. Roy. Soc. (London) [A] 180, 40 (1942); Rubber Chem. Tech. 15, 742 (1942).

[11] C. W. Bunn, Molecular structure and rubber-like elasticity. III. Molecular movements in rubber-like polymers, Proc. Roy. Soc. (Ĺondon) [A] 180, $82(1942)$.

[12] C. W. Bunn, The stereochemistry of the rubber molecule, Trans. Faraday Soc. 38, 372 (1942); Rubber Chem. Tech. 15, 704 (1942); 16, 775 (1943).

[13] C. W. Bunn and E. V. Garner, The crystal structure of rubber hydrochloride, J. Chem. Soc. 1942, 654 (1942); Rubber Chem. Tech. 16, 848 (1943).

[14] E. Bunschoten, Mededeel Rijksvoorlichtingsdienst Behoeve Rubberhandel Rubbernijverheid, Delft, No. 3, p. 37 (1921).

[15] C. M. Carson, Effect of storage on milled crude rubber, Ind. Eng. Chem. 23, 691 (1931); Rubber Chem. Tech. 4, 417 (1931).

[16] F. S. Conant and J. W. Liska, Some low-temperature properties of elastomers, J. Applied Phys. 15,, 767 (1944); Rubber Chem. Tech. 18, 318 (1945). 
[17] F. H. Cotton, Rational processing, Trans. Inst. Rubber Ind. 16, 303 (1941); Rubber Chem. Tech. 14, 762 (1941).

[18] R. B. Dow, Inhibition of crystallization of rubber by high pressure, J. Chem. Phys. 7, 201 (1939); Rubber Chem. Tech. 12, 496 (1939).

[19] H. Feuchter, Concerning racked rubber, its "melting line," and its density, Kautschuk 2, 260 and 282 (1926).

[20] H. Feuchter and E. A. Hauser, Concerning aging, hysteresis, and melting point as well as work capacity and work power of progressively racked rubber, Kautschuk 5, 194, 218, 245, and 276 (1929).

[21] J. E. Field, An X-ray study of the proportion of crystalline and amorphous components in stretched rubber, J. Applied Phys. 12, 23 (1941); Rubber Chem. Tech. 14, 555 (1941).

[22] S. D. Gehman, The contribution of X-ray research to the knowledge of rubber, Chem. Rev. 26, 203 (1940).

[23] S. D. Gehman and J. E. Field, An X-ray investigation of crystallinity in rubber, J. Applied Phys. 10, 564 (1939); Rubber Chem. Tech. 12, 706 (1939).

[24] S. D. Gehman and J. E. Field, Observations on the X-ray structure of rubber and the size and shape of rubber crystallites, J. Applied Phys. 15, 371 (1944); Rubber Chem. Tech. 1\%, 640 (1944).

[25] A. Goetz and S. S. Goetz, Vitrification and crystallization of organic cells at low temperatures; J. Applied Phys. 9, 718 (1938).

[26] F. von Göler and G. Sachs, The kinetics of crystallization phenomena, Z. Physik. 7\%, 281 (1932).

[27] K. Gottlob, Technology of Rubber, p. 319. Translated into English by J. L. Rosenbaum (Maclaren \& Sons. Ltd., London, 1927).

[28] E. A. Hauser, M. Hünemörder, and P. Rosbaud, New X-ray studies on rubber and related substances, Kautschuk 3, 228 (1927).

[29] E. A. Hauser and P. Rosbaud, X-ray studies on rubber and similar substances, Kautschuk 3, 17 (1927).

[30] L. Hock, Chapter on Physics of Rubber, p. 421 in Memmler's Science of Rubber. Translated by R. F. Dunbrook and V. N. Morris. (Reinhold Publishing Corporation, New York, N. Y., 1934.)

[31] L. Hock. Theory of the Joule effect in rubber, Z. Elektrochem. 31, 404 (1934).

[32] W. L. Holt and A. T. McPherson, Change of volume of rubber on stretching; effects of time, elongation, and temperature, J. Research NBS 17, 657 (1936) RP936; Rubber Chem. Tech. 10, 412 (1937).

[33] W. A. Johnson and R. F. Mehl, Reaction kinetics in processes of nucleation and growth, Trans. Am. Inst. Mining Met. Engrs. 135, 416 (1939).

[34] J. R. Katz, X-ray spectrographic investigations of stretched rubber and their possible significance in the problem of the elastic properties of this material, Naturwissenschaften 13, 410 (1925).

[35] J. R. Katz, Crystal interferences in rubber and other polyprenes, Gummi-Ztg. 41, 1 (1927).

[36] J. R. Katz, The freezing of raw rubber. X-ray part, Kautschuk 5, 6 (1929).

[37] J. R. Katz, X-ray spectrography of polymers and in particular those having a rubber-like extensibility, Trans. Faraday Soc. 32, 77 (1936); Rubber Chem. Tech. 9, 357 (1936).

[38] J. R. Katz and K. Bing, Is raw rubber partially crystalline, Z. angew. Chem. 38, 439 (1925).

[39] F. Kirchhof, Raw rubber-a fibrous material, Kautschuk 2, 151 (1926).

[40] W. Kirsch, Equilibria between crystals and melts in rubber and their dependency on temperature and pressure, Dissertation, published by Trillsch \& Huther, Berlin, 1937.

[41] H. Mark, Phase transitions and elastic behavior of high polymers, Ind. Eng. Chem. 34, 449 (1942); Rubber Chem. Tech. 15, 452 (1942).

[42] T. H. Messenger and J. R. Scott, Softening and freezing of crepe. J. Research Assn. Brit. Rubber Mfrs. 5, 64 (1936); Rubber Chem. Tech. 10, 7 (1937).

[43] K. H. Meyer and H. Mark, Rubber, Ber. Deut. Chem. Ges. 61, 1939 (1928).

[44] K. H. Meyer, G. von Susich, and E. Valko, The elastic properties of the organic high polymers and their kinetic significance, Kolloid-Z. 59, 208 (1932).

[45] P. Mondain-Monval, Investigations of the allotropy and crystallization of vitreous materials, Ann. chim. 3, 5 (1935).

[46] E. Ott, Concerning the molecular size of rubber and gutta percha, Naturwissenschaften 14, 320 (1926). 
[47] E. Ott, X-ray investigations on rubber, J. Am. Chem. Soc. 52, 4612 (1930); Rubber Chem. Tech. 4, 82 (1931).

[48] C. Park, On the crystallization of crude rubber, Mem. Coll. Sci., Kyoto Imp. Univ. [A] 22, 13 (1939); J. Soc. Rubber Ind. Japan 12, 462 (1939) (In English); Rubber Chem. Tech. 12, 778 (1939).

[49] C. Park, Second report of the investigation of the crystallization of crude rubber, Mem. Coll. Sci., Kyoto Imp. Univ. [A] 22, 259(1 939). (In English); Rubber Chem. Tech. 13, 539 (1940).

[50] G. S. Parks, The amorphous and crystalline forms of rubber hydrocarbon, J. Chem. Phys. 4, 459 (1936); Rubber Chem. Tech. 10, 135 (1937).

[51] S. S. Pickles, The consistency of rubber and rubber compounds, India Rubber J. 67, 69 (1924).

[52] R. Pummerer and G. von Susich, Crystallized rubber Kautschuk 7, 117 (1931). Translated in Rubber Chem. Tech. 5, 245 (1932).

[53] A van Rossem and J. Lotichius, The "freezing" of raw rubber, Kautschuk 5, 2 (1929). Translated in Rubber Chem. Tech. 2, 378 (1929).

[54] M. Ruhemann and F. Simon, A contribution to the knowledge of the physical properties of rubber, Z. physik. Chem. [A] 138, 1 (1928).

[55] $\mathrm{H}$ Sachse, The thermal effects accompanying the spontaneous density increase in raw rubber, Gummi-Ztg. 43, 2216 (1929).

[56] W. H. Smith and N. P. Hanna, Comparison between the observed density of crystalline rubber and the density calculated from X-ray data, J. Research NBS 27, 229 (1941) RP1416; Rubber Chem Tech. 15, 265 (1942).

[57] W. H. Smith and C. P. Saylor, Ether-insoluble or gel rubber hydrocarbon, its solution, crystallization, and properties, J. Research NBS 13, 453 (1934) RP719; Rubber Chem. Tech. 8, 214 (1935).

[58] W. H. Smith and C. P. Saylor, Optical and dimensional changes which accompany the freezing and melting of Hevea rubber, J. Research NBS $\mathbf{2 1}$, 257 (1938) RP1129; Rubber Chem. Tech. 12, 18 (1939).

[59] W. H. Smith, C. P. Saylor, and H. J. Wing, Preparation and crystallization of pure ether-soluble rubber hydrocarbon: Composition, melting point, and optical properties, BS J. Research 10, 479 (1933) RP544; Rubber Chem. Tech. 6, 351 (1933).

[60] G. von Susich, The fusion curve of natural rubber. Naturwissenschaften 18, 915 (1930). Translated in Rubber Chem. Tech. 4, 211 (1931).

[61] G. Tammann, Der Glaszustand (Leopold Voss, Leipzig, 1933).

[62] G. Tammann and E. Jenckel, The crystallization velocity and the number of nuclei in glycerine and their dependence on temperature. Z anorg, allgem. Chem. 193, 76 (1930).

[63] W. E. Thibodeau and A. T. McPherson, Photoelastic properties of soft vulcanized rubber, J. Research NBS 13, 887 (1934) RP751; Rubber Chem. Tech. 8, 183 (1935).

[64] F. Thiele and E. Wurm, Chapter on Patentgummi in E. A. Hauser, Handbuch der Gesamten Kautschuktechnologie, vol. II (Union Deutsche Verlagsgesellschaft Berlin, 1935.)

[65] P. A. Thiessen and W. Kirsch, Crystallization of rubber by pressure, Naturwissenschaften 26, 387 (1938). Translated in Rubber Chem. Tecb. 12, $12(1939)$.

[66j P. A. Thiessen and W. Kirsch, The crystallization of weakly-vulcanized rubber by pressure, Naturwissenschaften $2 \%, 390$ (1939). Translated in Rubber Chem. Tech. 13, 48 (1940).

[67] P. A. Thiessen and W. Wittstadt, Forced and spontaneous changes in the arrangement of the molecules in stretched rubber. Crystals and fused phase in stretched rubber. Z. Physik. Chem. [B] 41, 33 (1938). Translated in Rubber Chem. Tech. 12, 736 (1939).

[68] L. R. G. Treloar, Elastic recovery and plastic flow in raw rubber, Trans. Faraday Soc. 36, 538 (1940); Rubber Chem. Tech. 13, 795 (1940).

[69] L. R. G. Treloar, Crystallization phenomena in raw rubber, Trans. Faraday Soc. 3y, 84 (1941); Rubber Chem. Tech. 15, 251 (1942).

[70] L. R. G. Treloar, The structure and elasticity of rubber. Reports on progress in physics 9, 113 (Physical Society, London, 1943).

[71] M. Volmer and M. Marder, The theory of linear crystallization velocity of undercooled melts and undercooled solid modifications Z. physik. Chem. [A] 154, 97 (1931). 


\section{Journal of Research of the National Bureau of Standards}

[72] G. S. Whitby, Physical properties of raw rubber, chapter 2 in Davis and Blake: Chemistry and technology of rubber, p. 102 (Reinhold Publishing Corporation, New York, N. Y., 1937).

[73] A. J. Wildschut, On the proportion of crystalline and amorphous components in stretched vulcanized rubber. J. Applied Phys. 17, 51 (1946).

[74] W. Wittstadt, External influence and the internal state of rubber, Kautschuk 15, 11 (1939). Translated in Rubber Chem. Tech. 12, 488 (1939).

[75] L. A. Wood, The beta-anomaly of Ruhemann and Simon in rubber, J. Chem. Phys. 10, 403 (1942).

[76] L. A. Wood, Crystallization phenomena in natural and synthetic rubbers, chapter 2 in Mark and Whitby: Advances in colloid science, 2, 57 (Interscience Publishers, Inc., New York, N. Y., 1946).

[77] L. A. Wood, N. Bekkedahl, and R. E. Gibson, Effect of pressure on the melting of crystalline rubber, J. Chem. Phys. 13, 475 (1945); J. Research NBS 35, 375 (1945) RP1677.

[78] L. A. Wood, N. Bekkedahl, and C. G. Peters, Application of the interferometer to the measurement of dimensional changes in rubber, J. Research NBS 23, 571 (1939) RP1253; Rubber Chem. Tech. 13, 290 (1940).

Washington, February 21, 1946. 